At this time the patient's serum lactate, pyruvate, folate, red blood cell folate serum $\mathrm{B}_{12}$, zinc, copper, cholesterol, and the lipoprotein values were all normal. Activities of alanine aminotransferase, aspartate aminotransferase, alkaline phosphatase, and $\gamma$-glutamyltransferase were raised.

After supplementation with vitamin $E$ for 6 months the nystagmus had resolved. After 18 months of treatment the ataxia had lessened, hand coordination was improved, and Romberg's sign was negative. She was still areflexic.

\section{Discussion}

A neurological syndrome secondary to vitamin E deficiency which has responded to vitamin E supplements has been reported in adults with cystic fibrosis. ${ }^{45}$ Our patient resembled these previous reports but presented much earlier. This was presumably because of impaired bile salt solubility of the vitamin in addition to pancreatic insufficiency. Luminal bile salt concentrations were likely to have been reduced in our patient. Firstly she had multiple resections of the ileum, the site of the active reabsorption of bile salts; secondly, the situation would be exacerbated by stasis in the dilated jejunum producing a 'blind loop' effect; and finally biliary fibrosis would result in impaired biliary excretion.

Although this neurological complication seems to be relatively uncommon in cystic fibrosis, it is important to be aware of it. A careful neurological examination of these patients for evidence of cerebellar, posterior column, and peripheral nerve dysfunction is emphasised. Monitoring of serum vitamin $\mathrm{E}$ concentrations in all patients would be ideal and is recommended if possible, yet limited laboratory facilities for measurement make this impractical for many paediatricians. In patients with cystic fibrosis, 50 to $400 \mathrm{mg}$ daily of a water miscible product has generally resulted in normal plasma and tissue levels of $\alpha$-tocopherol. ${ }^{136}$ In the absence of laboratory facilities regular vitamin E supplementation of a water miscible preparation of vitamin $E$ is recommended in a dosage of 100 to $200 \mathrm{mg}$ daily. If there is severe malabsorption resulting in neurological dysfunction this oral preparation may not give adequate plasma concentrations and intramuscular vitamin E (50 to $100 \mathrm{mg} /$ week) may be required. ${ }^{4}$

We thank Hoffman La Roche and Company for the supply of water miscible vitamin $E$ and continued support for DPRM; Dr B Lake for neuropathology; and Mr D Forrest and Dr Harding for providing valuable information.

\section{References}

1 Farrell PM, Bieri JG, Fratantoni JF, Wood RE, di Sant 'Agnese PA. The occurrence and effects of human vitamin $E$ deficiency. A study in patients with cystic fibrosis. J Clin Invest 1977;60;233-41.

2 Muller DPR, Lloyd JK, Wolff OH. Vitamin E and neurological function. Lancet 1983;i:225-8.

${ }^{3}$ Sung JH, Park SH, Mastri AR, Warwick WJ. Axonal dystrophy in the gracile nucleus in congenital biliary atresia and cystic fibrosis (mucoviscidosis): beneficial effect of vitamin $E$ therapy. J Neuropathol Exp Neurol 1980;39:584-97.

+ Elias E, Muller DPR, Scott J. Association of spinocerebellar disorders with cystic fibrosis or chronic childhood cholestasis and very low serum vitamin E. Lancet 1981;ii:1319-21.

5 Umetsu DT, Conture P, Winter HS, Kagan BM, Bresnan MJ, Lux SE. Degenerative neurological disease in patients with acquired vitamin E deficiency. Pediatr Res 1980;14:512.

- Bieri JG, Corash L, Hubbard Van S. Medical uses of vitamin E. $N$ Engl J Med 1983;308:1063-71.

Correspondence to (no reprints available) Dr A Bye, 2A Adolphus Street, Naremburn 2065, Australia.

Received 24 September 1984

\title{
Loss of breast milk nutrients during tube feeding
}

\section{R J STOCKS, D P DAVIES, F ALLEN, AND D SEWELL}

Department of Child Health, University of Leicester and Neonatal Unit Leicester Royal Infirmary, and Department of Human Biology, University of Loughborough

SUMmary Nutrient losses from banked breast milk during tube feeding were determined from laboratory models. Large fat losses occurred, continuous feeding giving rise to significantly greater losses than bolus feeding. More fat loss occurred with low flow rates and there were also significant protein losses.
The effects of delivery and handling on bank breast milk nutrients have commanded much less attention than the nutrient properties themselves. The composition of milk in the feeding syringe may not be the same as that which enters the infant's gastrointestinal tract; significant energy losses have been shown to be lost during the passage down feeding tubes. ${ }^{12}$ This study compares fat losses in con- 
tinuous infusions and intermittent boluses of milk and also investigates protein and $\operatorname{IgA}$ loss.

\section{Material and methods}

Laboratory models simulating feeding systems used in clinical practice on our neonatal unit were designed. Continuous infusion feeding utilised a standard 4 FG feeding tube connected to a $60 \mathrm{ml}$ reservoir syringe by a $150 \mathrm{~cm}$ manometer line. After filling the system with a four hour supply of milk, the syringe was positioned vertically in a pump and for four hours milk was infused continuously into the tubing at varying rates. Milk emerging from the end of the feeding tube was collected into glass containers over each hour of this period and the four aliquots set aside for analysis.

Intermittent bolus feeding utilised a feeding tube directly connected to a 10 or $20 \mathrm{ml}$ syringe. One hour's supply of milk was placed in a syringe and this bolus infused over about five minutes by gentle manual pressure on the piston; the milk aliquots were collected similarly for analysis. After rinsing with water the same tube was used for the further bolus infusions, although the syringe was changed.

Donations of human milk from our milk bank were used; the milk had previously been cooled and pasteurised and was kept frozen before consumption but was thawed at room temperature before the experiments.

Each batch of milk was analysed for fat content (creamatocrit), ${ }^{3}$ IgA content (radial immunodiffusion) and protein content (Biuret). These analyses were repeated on the aliquots obtained after simulated continuous or bolus feeds.

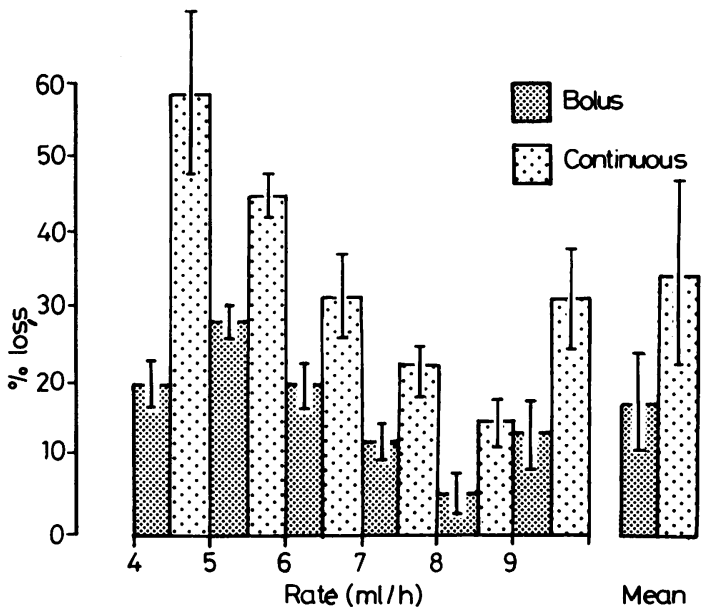

Fig. 1 Fat loss: variation in relation to rate and method of feeding.

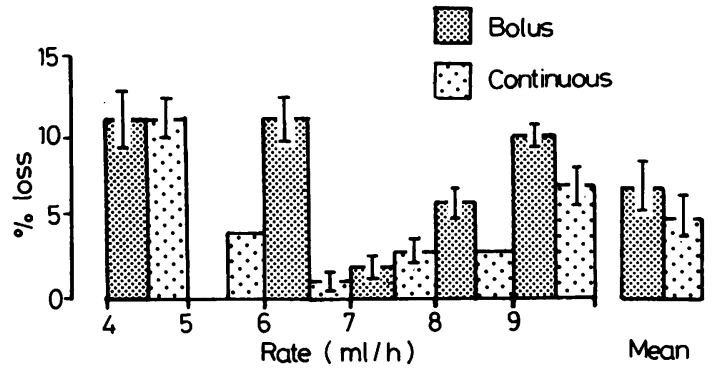

Fig. 2 Protein loss: variation in relation to rate and method of feeding.

\section{Results}

The mean fat losses at different feeding rates for bolus and continuous methods are shown in Fig. 1. The differences between the two techniques were significant $(\mathrm{P}<0.05)$-mean fat losses being $17 \%$ and $34 \%$ for bolus and continuous feeding respectively. There was a significantly inverse correlation between fat loss and flow rates for both techniques $\left(r^{2}=0.865\right.$ and 0.922 respectively).

Protein losses are shown in Fig. 2. Although the mean losses were significant $(\mathrm{P}<0.05)$ at $7 \%$ and $5 \%$ for bolus and continuous feeding respectively, there was no significant difference between the techniques nor any correlation of loss with flow rate. The mean losses of IgA were small (less than $1 \%$ ) and did not reach statistical significance.

\section{Discussion}

The question of what milk should be given to preterm infants has attracted greater attention than how it should be delivered. Three studies describing loss of energy or fat have highlighted the importance of delivery technique in tube feeding. Spencer ${ }^{4}$ showed mean fat losses of $34 \%$ and $19 \%$ respectively with drip infusions and pump driven syringes: most tube fed infants were receiving less than 0.42 $\mathrm{MJ} / \mathrm{kg} /$ day (100 Kcals/kg/day). Brooke ${ }^{1}$ recorded up to $24 \%$ energy losses in a continuous system using a burette pump: fast rates of $10 \mathrm{ml} /$ hour and greater were studied and there was no variation in energy losses with infusion rates. Narayanan ${ }^{6}$ described a method of reducing fat accumulation in the reservoir syringe by using eccentric nozzle syringes set at an angle.

The present study extends these investigations by showing that continuous infusions result in greater fat losses compared with intermittent boluses, and that slow flow rates were associated with greater fat loss which is relevant to the smallest, low birth- 
weight babies. Doubts about the precision of the creamatocrit method must be tempered by the fact that it has an accuracy in the region of $10 \%(95 \%$ confidence limits). ${ }^{4}$ Protein loss was considerable but not related to technique or flow rate. The $\operatorname{IgA}$ loss has been spared, possibly due to differences in physico-chemical properties of milk proteins.

Two important clinical implications emerge. Firstly, these fat and protein losses will tend to invalidate any metabolic studies of the influence of feeding human milk on growth of low birthweight babies. It is possible that this is why Spencer was unable to show any correlation between energy intake and weight gain. ${ }^{4}$ Similarly, nutrient losses may be a potent cause for this lower weight gain showed by babies fed continuously by the nasojejunal route compared with those fed with intermittent boluses. ${ }^{5}$

Secondly, the extremely variable nutrient losses observed with continuous infusions must question the value of this method of feeding small infants particularly when there is no convincing evidence of its clinical benefit. If human milk is to be given this should be by bolus wherever possible.

The results of this study will most likely strengthen further the conviction of those who have recently questioned the value of human milk for preterm infants. We believe that it is premature as yet to discourage the use of human milk. Those who advocate more complicated formula feeding must show that it gives better short term results in terms of freedom from metabolic or iatrogenic disorder, and that long term growth and neurodevelopmental potentials are fulfilled. Those who believe in the desirability of human milk must pay attention to both the collection of milk and its delivery.

\footnotetext{
References

' Brooke OG, Barley J. Loss of energy during continuous infusions of breast milk. Arch Dis Child 1978;53:344-5.

${ }^{2}$ Spencer SA, Hull D. Fat content of expressed breast milk: a case for quality control. $\mathrm{Br}$ Med J 1981;282:99-100.

${ }^{3}$ Lucas A, Gibbs JAH, Lyster RLJ, Baum JD. Creamatocrit: a simple clinical technique for estimating fat concentration and energy value of human milk. $\mathrm{Br}$ Med $J$ 1978;i:1018-20.

${ }^{4}$ Spencer SA, Hendrickse W, Roberton D, Hull D. Energy intake and weight gain of very low birth weight babies fed raw expressed breast milk. $\mathrm{Br}$ Med $J$ 1982;285:924-6

5 Whitfield MF. Poor weight gain of the low birth weight infant fed naso-jejunally. Arch Dis Child 1982:57:597-601.

${ }^{6}$ Narayanan I, Singh B, Harvey D. Fat loss during feeding of human milk. Arch Dis Child 1984;59:475-7.
}

Correspondence to Dr R J Stocks, Department of Child Health, Leicester Royal Infirmary, Leicester LE2 7LX.

Received 31 August 1984

\title{
Vascular basis for malformations in a twin
}

\author{
T J DAVID \\ Department of Child Health, University of Manchester
}

SUMMARY A twin is described who was born with ileal atresia and hydranencephaly, the co-twin having died at about 24 weeks' gestation. If a macerated or autolysed twin is found at birth, the paediatrician should be alerted to the possibility of serious and not immediately obvious defects in the surviving infant.

The idea that malformations can only occur during embryogenesis in the first trimester is now out of date. Various cerebral defects clearly arise in the midtrimester. There is an association between the intrauterine death of a monozygotic twin and brain damage in the surviving twin. ${ }^{1}$ It has been suggested that death of the twin causes intrauterine disseminated intravascular coagulation, and that feto-fetal exchange of thromboplastic material from the dead fetus through vascular shunts in a monochorionic placenta causes cerebral infarction in the surviving twin. $^{2} 3$ Ileal atresia is thought to result from interference to the blood supply to a segment of the fetal bowel. ${ }^{4}$ This report describes a twin who was born with ileal atresia and hydranencephaly, the cotwin having died in the midtrimester of pregnancy.

\section{Case report}

This was the second pregnancy of a healthy 24 year old mother and 23 year old father. The first child was a healthy girl aged 2 years, there was no family history of malformations, and no consanguinity. No drugs were taken in pregnancy, which was normal until 24 weeks' gestation when twins were diagnosed by ultrasound scan. A scan at 26 weeks suggested that one of the twins had died, and this was confirmed on subsequent scans. Spontaneous onset 